\title{
Hpa1 is a type III translocator in Xanthomonas oryzae pv. oryzae
}

\author{
Xuan Wang ${ }^{1}$, Liyuan Zhang ${ }^{1}$, Hongtao $\mathrm{Ji}^{1,2}$, Xuyan Mo${ }^{1}$, Ping $\mathrm{Li}^{1}$, Junzhi Wang ${ }^{1}$ and Hansong Dong ${ }^{1 *}$ (D)
}

\begin{abstract}
Background: Pathogenic Gram-negative bacteria interact with their eukaryotic hosts by deploying the type III translocon to inject effector proteins into the cytosol of eukaryotic cells. The translocon compositions, the number and biochemical characteristics of type III translocators in animal-pathogenic bacteria have been well elucidated, but information is lacking for plant-pathogenic bacteria. With extensive studies on biological functions of the Hpa1 protein secreted by the type III secretion system in Xanthomonas oryzae pv. oryzae (Xoo), we show here that Hpa1 is a type III translocator based on measurements of two proteins categorized as transcription activator-like (TAL) effector.

Results: Hpa1 was functionally associated with the TAL effector PthXo1 or AvrXa10 by genetic analysis of the wildtype $X_{0 O}$ strain and related mutants or recombinant strains. Inoculation experiments suggested that Hpa1 is required not only for the virulent role of PthXo1 in the susceptible rice variety Nipponbare, but also for the avirulent function of AvrXa10 on the resistant rice variety IRBB10. Hpa1 is unrelated to the secretion of PthXo1 and AvrXa10 out of bacterial cells. However, Hpa1 is critical for both TAL effectors to be translocated from bacterial cells into the cytosol of rice cells based on replicate experiments performed on the susceptible and resistant varieties, respectively. Hpa1-mediated translocation of PthXo1 is coincident with induced expression of rice SWEET11 gene, which is the regulatory target of Pth $X_{0} 1$, resulting in the occurrence of the bacterial blight disease in the susceptible rice variety. By contrast, the immune hypersensitive response is induced in agreement with induced expression of rice Xa10 gene, which is the target of AvrXa10, only when AvrXa10 is translocated from bacteria into cells of the resistant rice variety. All the virulent or avirulent performances of the TAL effectors are nullified by directed mutation that removes the a-helix motif from the Hpa1 sequence.
\end{abstract}

Conclusions: The genetic and biochemical data demonstrate that Hap1 is a type III translocator at least for TAL effectors PthXo1 and AvrXa10. The effect of the directed mutation suggests that Hpa1 depends on its a-helical motif to fulfil the translocator function.

\section{Background}

Many effector proteins of Gram-negative bacteria, which are plant [1] or animal [2,3] pathogens, are secreted by the type III secretion system (T3SS). Subsequently, effectors must be translocated into the cytosol of eukaryotic cells in order to fulfill virulent or avirulent roles [1, 4]. Effector translocation relies on the type III translocon, which is made of hydrophilic and hydrophobic proteinaceous translocators $[2,3,5]$. The distinct translocators make up the translocon by complicated monogenous

\footnotetext{
*Correspondence: hsdong@njau.edu.cn

'Department of Plant Pathology, College of Plant Protection, Nanjing

Agricultural University, Nanjing 210095, Jiangsu Province, China

Full list of author information is available at the end of the article
}

and heterogeneous molecular interactions and by associations with recognition compounds at the plasma membranes (PMs) of eukaryotic cells [2, 3]. In the current model $[2,5]$, hydrophilic translocators form complexes at the tip [6,7] of proteinaceous pili in plant pathogens or proteinaceous needles in animal pathogens and associate with hydrophobic counterparts, which oligomerize into the target PM $[8,9]$. The resulting translocon consists of an inner conduit that is connected to a pilus or needle channel and opens into eukaryotic cells, thereby allowing the direct injection of effectors into the cytosol of eukaryotic cells $[2,3,9]$.

All hydrophilic translocators so far identified in plantpathogenic bacteria are characteristic of harpins, which

(c) The Author(s). 2018 Open Access This article is distributed under the terms of the Creative Commons Attribution 4.0 International License (http://creativecommons.org/licenses/by/4.0/), which permits unrestricted use, distribution, and 
belong to T3SS accessory proteins and contain a unitary hydrophilic domain or an additional enzymatic domain [5, 8-12]. While two-domain harpins may target the bacterial periplasm or plant cell walls to facilitate pilus growth $[8,10,11]$, one-domain harpins localize to plant PMs, with a potential role in the translocon assembly $[8,9,13,14]$. Eukaryotic PM sensors, which are either lipids $[2,3,15]$ or proteins $[13,14]$, are assumed to be indispensable for translocator recognition and translocon formation $[2,3,5,6]$.

We have extensively studied multiple functions of Hpa1 $[5,14,16]$, a one-domain harpin [17] from Xanthomonas oryzae pv. oryzae (Хoo). Хoo causes bacterial blight in rice (Oryza sativa) through effector proteins, either transcription activator-like (TAL) effectors or non-TAL effectors like Xops, Xanthomonas outer proteins $[4,18]$. TAL effectors were found initially in plant-pathogenic bacteria of the Xanthomonas genus [19] and proved then to include previously designated Avr proteins present in the same pathogens [20]. TAL and non-TAL effectors are secreted along with harpins by the T3SS in a chronological pattern $[2,21]$ and then translocated into plant cells to play a virulent or avirulent role depending on plant varieties [1, 4]. Like the movement of all bacterial effectors, TAL and non-TAL protein translocation is a moment travel through a translocon hypothetically made of translocators [2, 22], which include one-domain harpins, such as Hpa1, in plant pathogenic bacteria $[5,8,9,12]$. However, the role of Hpal in effector translocation has not been demonstrated.

Hpa1 comprises 139 amino acids with a molecular mass of $15 \mathrm{kD}$ and carries a pair of $\alpha$-helical coiled-coil motif at sites 37-52 and 87-102 [23]. While the $\mathrm{N}$-terminal $\alpha$-helix governs Hpa1 oligomerization [23], the first 53 residues determine its bioactivities in plants [5, 14, 24, 25]. Hpa1 affects virulence of the Xoo strain PXO99 in susceptible japonica rice variety Nipponbare [5] while the virulence is provided by the TAL effector PthXo1 [26]. By contrast, the TAL effector AvrXa10 of the Xoo strain PXO86 plays an avirulent role in resistant indica rice variety IRBB10 [27]. While AvrXa10 activates the host resistance gene $\mathrm{Xa10}$ to confer the immune or hypersensitive response (HR) in IRBB10 [27], PthXo1 induces virulence by activating the host susceptibility gene SWEET11 (synonym Os8N3) in Nipponbare [26]. We report here that Hpal is a type III translocator and executes this function through the $\alpha$-helical motifs.

\section{Methods}

\section{Plant growth}

Seeds of Nipponbare were initially provided by our colleague Professor Hongsheng Zhang (College of Agronomy, Nanjing Agricultural University) and reproduced and maintained in this lab. Rice seeds were germinated in flat plastic trays filled with a substrate containing peat, sand, and vermiculite $(1: 1: 1 \mathrm{v} / \mathrm{v})$. Three days later, the germinal seedlings were moved into 12 -L pots ( 2 plants per pot) filled with soil from a local rice grower field. Seeds were incubated and the plants were grown in environment-controlled chambers under $28{ }^{\circ} \mathrm{C}, 12$-h light at $250 \pm 50 \mu \mathrm{mol}$ quanta $/ \mathrm{m}^{2} / \mathrm{sec}$, and a relative humidity of $85 \%$. Tobacco plants were grown in a greenhouse for two months prior to use.

\section{Bacterial strains and molecular vectors}

Bacterial strains and plasmid vectors used and created in the present study and information on antibiotic resistance are listed in Additional file 1: Table S1. Escherichia coli was grown at $37{ }^{\circ} \mathrm{C}$ in Luria-Bertani broth (LB) or on LB agar (LA) plates with the appropriate antibiotics. Xoo strains were cultured at $28{ }^{\circ} \mathrm{C}$ on nutrient broth (NB) or NA agar (NA) medium [28]. Bacteria were cultured on medium supplemented with $100 \mu \mathrm{g} / \mathrm{mL}$ ampicillin, $100 \mu \mathrm{g} / \mathrm{mL}$ spectinomycin, or $50 \mu \mathrm{g} / \mathrm{mL}$ kanamycin.

\section{Bacterial gene modifications}

The hpa1 and pthXo1 genes were deleted from PXO99 by using the unmarked deletion method [23]. Upstream and downstream flanking partial sequence fragments of hpa1 or pthXo1 were amplified from the PXO99 genomic DNA and connected together by overlapped fusion-PCR using specific primers (Additional file 1: Table S2). Every PCR product was confirmed by sequencing and then cloned into the vector pK18sacB by digestion with $\mathrm{BamHI}$ and $X b a \mathrm{I}$ and ligation with T4 ligase (Thermo Scientific). Every recombinant vector was introduced into PXO99 cells by electroporation, followed by single-colony selection on kanamycin-containing and sugar-absent NA plates. Colonies from single crossovers were transferred to $\mathrm{NB}$ broth, grown at $28{ }^{\circ} \mathrm{C}$ for $12 \mathrm{~h}$ and then transferred onto plates containing NA and 10\% sucrose. Sucrose-resistant colonies were replica streaked onto NA plates with and without kanamycin supplementation. Colonies resulting from double crossover events were selected based on kanamycin-negative and sucrose-positive traits, and unmarked mutants were confirmed by PCR amplification of hpa1 and pthXo1, respectively. To create

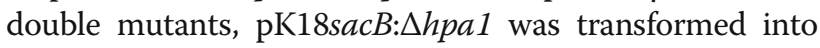
the $\Delta p t h X o 1$ mutant.

Different tags were attached to the 3 '-terminus of pthXo1 or avrXa10 in the pZWpthXo1 and pZWavrXa10 plasmid vectors. To create a cya-fused gene, a 1,218-bp cya fragment encoding amino acids 2-406 of the Cya protein was amplified from plasmid pMS107 and prefixed with the last 51-bp region of $p t h X o 1$ that contained a $S a c I$ recognition site. The recombinant sequence was inserted into pZWpthXo1 at the SacI site. A similar method was used for the construction of avrXa10-cya. To construct 
pthXo1-blaM, blaM was amplified from plasmid pBR322 using specific primers that contained a SalI site. The confirmed PCR product was inserted into the pthXo1 sequence at the SalI site in pZWpthXo1, and avrXa10-blaM was similarly constructed [29]. Every recombinant vector was linearized with HindIII and cloned into the pHM1 vector for genetic complementation. The hpa1pthXo1 and hpalavrXa10 double complementary vectors were constructed using two steps. First, the hpal sequence that was linked its own promoter was cloned into pHM1 between the PstI and KpnI sites. Second, pZWavrXa10 or pZWpthXo1 was linearized using HindIII and inserted into the HindIII site of pHM1hpa1. Complementation or transformation was performed by electroporation.

\section{Bacterial virulence/avirulence evaluation}

Overnight Xoo NA cultures were washed twice and resuspended in sterile water to generate inoculum suspensions with an optical density of $\mathrm{OD}_{600}=0.5$. A bacterial suspension was inoculated on leaves of 2-week-old rice seedlings by infiltration with needleless syringes at 3 sites per leaf. Alternatively, a bacterial suspension was inoculated on leaves of 2-month-old adult rice plants by the leaf clipping method [28]. Symptoms were scored by photographing or measuring lesion lengths or HR areas. Bacterial growth in rice leaves was measured by harvesting 10 leaves for each treatment after needleless syringes inoculation.

\section{Protein secretion and translocation assays}

TAL effector-related PXO99 strains were grown in NB broth at $28{ }^{\circ} \mathrm{C}$ with the appropriate antibiotics to logarithmic phase. Bacterial cells were harvested by centrifugation. The precipitated bacterial pellet was washed twice with sterile water and resuspended in $100 \mathrm{~mL}$ of type III-inducing XOM2 liquid media [30] to an of $\mathrm{OD}_{600}=0.6$. This XOM2 suspension was supplied with the appropriate antibiotics and incubated in a $28{ }^{\circ} \mathrm{C}$ shaker at $220 \mathrm{rpm}$ for $16 \mathrm{~h}$. XOM2 cultures were then separated into cell pellet and supernatant fractions by centrifugation. The proteins in the pellet and supernatant were extracted by sonication and by precipitation with $12.5 \%$ trichloroacetic acid, respectively [28]. Proteins were separated by $6 \%$ SDS-PAGE and transferred to Immobilon-P membranes (Millipore) for immunoblotting analyses using a Cya antibody (Santa Cruz) or $\beta$-lactamase antibody (Abcam). The ampicillin resistance protein $\beta$-lactamase protein is encoded by the pZWtal-cya vector (Additional file 1: Table S1), remains cell-bound unless non-specific cell leakage occurred, and was used as a control for nonspecific cell lysis. Protein blots were incubated with the specific antibody and hybridized to horseradish peroxidase-conjugated goat antimouse immunoglobulin G from the BeyoECL Plus kit (Beyotime).
The Cya reporter assay was performed on two-week-old rice seedlings inoculated with Cya-related Xoo strains. Bacterial suspensions were prepared from NA cultures and adjusted to an OD600 $=0.5$. Each suspension was infiltrated into intercellular spaces of expanded leaves at three sites per leaf. At $12 \mathrm{hpi,} 5$-cm-long leaf segments that covered infiltration sites were excised from inoculated leaves, frozen in liquid nitrogen in a mortar, and ground with a ceramic pestle to a fine powder. The leaf powder was suspended in $350 \mu \mathrm{L}$ of $0.1 \mathrm{M} \mathrm{HCl}$, followed by brief centrifugation [29]. The supernatant was analyzed with a cAMP ELISA detection kit (GenScript) to determine intracellular cAMP concentrations. Total proteins in each sample for normalization were quantified by using a BCA protein assay kit (TransGen Biotech).

\section{Gene expression analysis}

Total RNA was isolated from leaves or protoplasts by using TRIzol (Invitrogen) and treated with DNase I (Invitrogen) to remove DNA. cDNA was synthesized from RNA by using a PrimeScript RT Master Mix (TaKaRa). Quantitative real-time PCR was performed in an ABI7500 Real-Time PCR system (Applied Biosystems) using specific primers (Additional file 1: Table S2) and a SYBR Premix Ex Taq kit (TaKaRa). The constitutively expressed rice Ubi1 gene was used as reference. The average expression level of a tested gene was quantified as transcript amount ratio to the reference gene.

\section{Bacterial protein preparation}

To prepare proteins used in plant and protoplast treatments, hpa1, hpa1 $\Delta N 36$, hpa $1 \Delta N \alpha$, hpa1 $1 \mathrm{C \alpha}$, and $h p a 1 \Delta N C \alpha$ genes were cloned separately into a pET30a + vector (carrying His) or pET41a + (carrying GST-His) by using BamHI and HindIII. Fusion proteins were produced in BL21 under induction by IPTG according to the pET System Manual. Proteins were purified using ProteinIso Ni-NTA Resin (TransGen Biotech). Before use in plant and protoplast treatments, the Hpa1-His fusion protein was treated with an enterokinase (New England Biolabs) to remove the His tag. Purified proteins were prepared as aqueous solution stocks and their concentrations were determined using the $\mathrm{BCA}$ protein assay kit (TransGen Biotech). Every protein was used at a final concentration of $10 \mu \mathrm{g} / \mathrm{mL}$ in water [14].

\section{Data treatment}

All experiments were carried out at least three times with similar results. Quantitative data were analyzed with the IBM SPSS19.0 software package (IBM Corporation, Armonk, NY, USA; http://www-01.ibm.com/ software/analytics/spss/) according to instructions in a text book that describes in details analysis methods using IBM SPSS19.0. [31]. Homogeneity-of-variance in data was 
determined by Levene test, and formal distribution pattern of the data was confirmed by Kolmogorov-Smirnov test and P-P Plots [31, 32]. Then, data were analyzed by analysis of variance and least significant difference test [33-35].

\section{Results}

\section{Hpa1 contributes to the virulent role of PthXo1 on rice} variety Nipponbare

In order to analyze the functional relationship between Hpa1 and PthXo1, we generated PXO99 mutants $\Delta h p a 1, \Delta p t h X o 1$, and $\Delta h p a 1 \Delta p t h X o 1$ by sequence de-

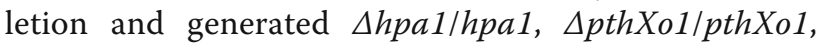
and $\Delta$ hpa1 $\Delta p t h X o 1 / h p a 1 / p t h X o 1$ strains by genetic complementation (Fig. 1). In leaf-top-clipping (Fig. 1a) and leaf-center-infiltrating (Fig. 2a) inoculation experiments performed on the susceptible rice variety Nipponbare, these bacteria displayed extensive variations in virulence levels. Virulence degrees were quantified as the length of blight lesion on leaves observed at 12 days post-inoculation (dpi) (Fig. 1b) and bacterial populations propagated in leaf tissues 3 dpi (Fig. 1c; Fig. 2b). Bacterial populations were given as logarithmic values of colony formation units (cfu) of bacterial cells after recovery from leaf tissues. Compared to the wild-type (WT) strain, the mutants displayed highly impaired virulence based on blight lesion length and in planta bacterial populations. Deleting hpa1, pthXo1, or both caused substantial reductions of in planta bacterial populations and blight lesion length, whereas complementation strains resembled WT in terms of virulence performance
(Figs. 1 and 2). In comparison, deleting hpa1 was much less inhibitive to PXO99 virulence than pthXo1 knockout, which almost completely nullified the bacterial virulence performance (Fig. 1a-c). This result confirms the previous finding that PthXo1 is a major determinant of the bacterial virulence [26] while Hpal plays a partial role in the virulence $[17,36]$. Moreover, the abilities of PXO99 to cause bacterial blight (Fig. 1a, b) and to multiply in leaf tissues (Fig. 1c) were significantly $(p<0.01)$ compromised by knockout of the $h r c V$ gene, which encodes an inner membrane protein essential for substrate docking into the T3SS [37]. Thus, PthXo1 requires T3SS to execute its virulence function.

\section{Hpa1 is required for the avirulent function of AvrXa10 on rice variety IRBB10}

While PXO99 was virulent, PXO99/avrXa10, which was generated by introducing avrXa10 into PXO99 cells, exhibited avirulence and induced the HR in leaves of the resistant rice variety IRBB10 (Fig. 2a). The HR appeared as brown necrotic lesion while necrosis became evident within $24 \mathrm{~h}$ post-inoculation (hpi) and was usually documented by leaf photography. Compared to the recombinant bacterial strain PXO99/avrXa10 carrying a functional hpa1 gene, the mutant $\Delta$ hpa1/avrXa10 generated by deleting hpal was highly impaired in the HR induction level (Fig. 2a). The impaired level of HR induction was coincident with a significant $(P<0.01)$ decrease in bacterial population of $\Delta$ hpa1/avrXa10 propagated during the period of HR development (Fig. 2b). These data suggest

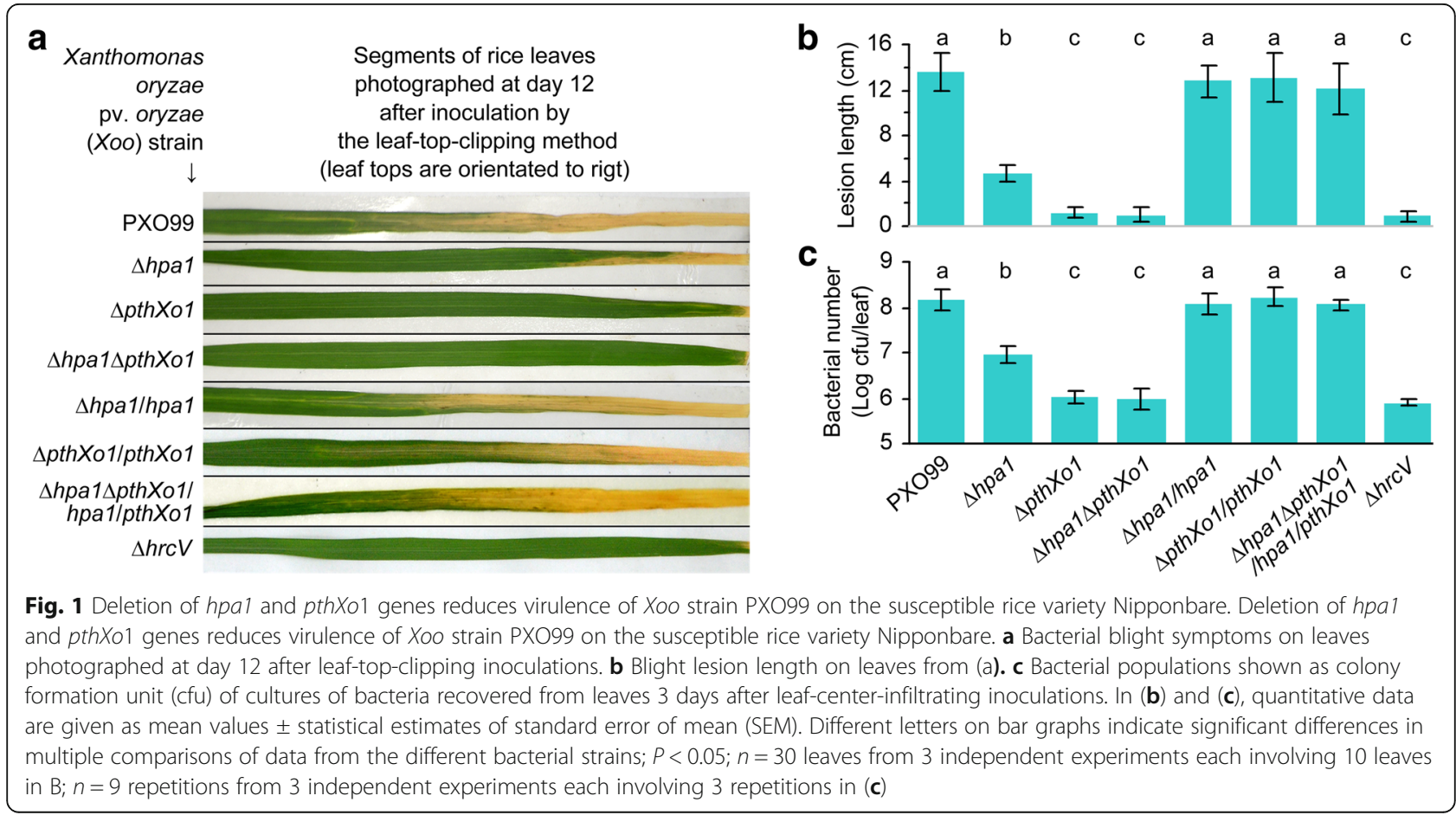



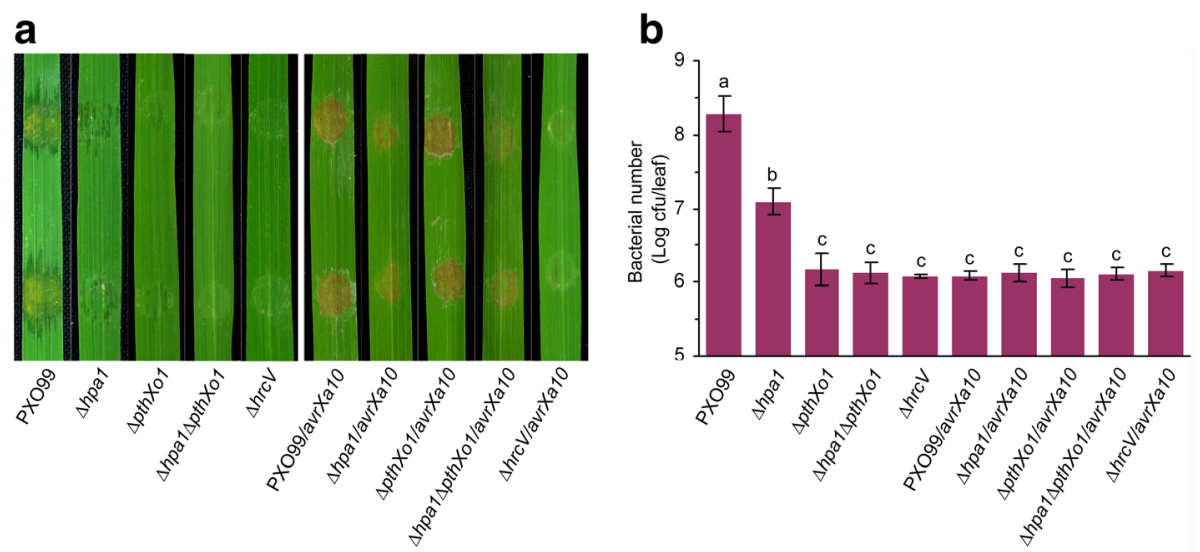

Fig. 2 Virulence of Xoo TAL effector-relevant strains on IRBB10. (a) Virulence of PXO99 WT and TAL effector-relevant mutants on IRBB10. Fourteenday-old IRBB10 seedlings were inoculated by leaf infiltration with every bacterial suspension of the indicated Xoo strains. Inoculated leaves were photographed at 5 days post-inoculation (dpi). (b) Bacterial populations propagated in leaf tissues were determined at 5 dpi. Quantitative data shown are means \pm statistical estimates of standard error of mean (SEM); different letters on bar graphs indicated significant difference in Duncan's multiple range tests; $P<0.05$; number of repetition $(n)=9$ from 3 independent experiments each involving 3 repetitions

the possibility that the $\Delta$ hpa1/avrXa10 strain incurs a partial loss of virulence due to hpal deletion and the avirulent function of AvrXa10. When the avrXa10 gene was introduced into the hpa1-containing pthXo1-knockout mutant $\Delta p t h X o 1$, resulting bacterial strain $\Delta p t h X o 1 /$ avrXa10 performed like PXO99/avrXa10 in the HR elicitation (Fig. 2a) and bacterial propagation (Fig. 2b). By contrast, both the HR induction and bacterial population were compromised by removing hpal from the $\Delta p t h X o 1 /$ avrXa10 genome (Fig. 2), confirming the critical effect of Hpa1 on the avirulent role of AvrX10. Moreover, the bacterial abilities to induce the HR (Fig. 2a) and to multiply in leaf tissues (Fig. 2b) were nullified by knockout of $h r c V$, suggesting that AvrXa10 requires T3SS to execute the subsequent function.

\section{Hpa1 does not affect secretion of PthXo1 and AvrXa10}

We analyzed protein secretion and translocation by using calmodulin-dependent adenylate cyclase (Cya), a eukaryotic cytoplasmic import marker [8]. We verified that Cya did not affect the virulent role of PthXo1 in Nipponbare plants inoculated by the leaf-top-clipping method (Fig. 3a) and also did not affect the avirulent activity of AvrXa10 in IRBB10 plants inoculated by the leaf-center-infiltrating method (Fig. 3b). Immunoblotting analysis revealed that PthXo1-Cya was secreted by T3SS in the presence of $\mathrm{HrcV}$ (Fig. 4a), an Xoo inner membrane protein essential for substrate docking into the T3SS [28, 37]. In contrast to PthXo1, $\beta$-lactamase used as a lysis control was not secreted, instead, it remained inside bacterial cells no matter whether hpal and $h r c V$ were present or absent (Fig. 4a), confirming the specificity in PthXo1 secretion by the T3SS. PthXo1-Cya was secreted equally well whether or not Hpa1 was deleted, suggesting that Hpa1 was not required for TAL effector secretion. Similarly, immunoblotting analysis indicated that AvrXa10 was secreted in a HrcV-dependent manner (Fig. 2b). By contrast, $\beta$-lactamase was not secreted irrespectively of the presence or absence of $h p a 1$ and $h r c V$ (Fig. 2b), confirming the specificity in AvrXa10 secretion by the T3SS. Hpa1 was dispensable for secretion of AvrXa10 since secretion amounts of AvrXa10-Cya were equivalent in the presence and absence of Hpal (Fig. 2b).

\section{Hpa1 is a translocator for PthXo1 and AvrXa10}

In the Cya reporter assay using rice leaves inoculated by the leaf-center-infiltrating method, Hpal was found to be critical for PthXo1 translocation from PXO99 cells into the cytosol of Nipponbare cells. In the assay, leaves were sampled at $12 \mathrm{hpi}$, and TAL effector translocation was quantified based on cAMP concentrations during effector-Cya activity in leaf cells (Fig. 5a). High concentrations of cAMP were detected in leaves inoculated with $\Delta p t h X o 1 / p t h X o 1-$ cya and $\Delta$ hpa1 $\Delta p t h X o 1 / h p a 1 / p t h X o 1-c y a$ strains, respectively. Cya activity was substantially decreased due to hpal deletion, as evidenced by a significant $(P<0.01)$ reduction in the cAMP content in leaves inoculated with the $\Delta$ hpa1 $\Delta$ pthXo1/pthXo1-cya strain (Fig. 5a).

Hpa1 was also indispensable for AvrXa10 translocation from PXO99/avrXa10-cya cells in the cytosol of IRBB10 cells. The effector translocation expressed as cAMP production by AvrXa10-Cya had higher quantities with hpa1containing PXO99 strains compared to hpa1-deleted ones (Fig. 5b). By contrast, the quantity of AvrXa10-Cya translocation was highly decreased by hpal deletion, as indicated by a significant $(P<0.01)$ reduction in the cAMP content in leaves inoculated with the $\Delta$ hpa1/avrXa10-cya strain (Fig. 5b). 


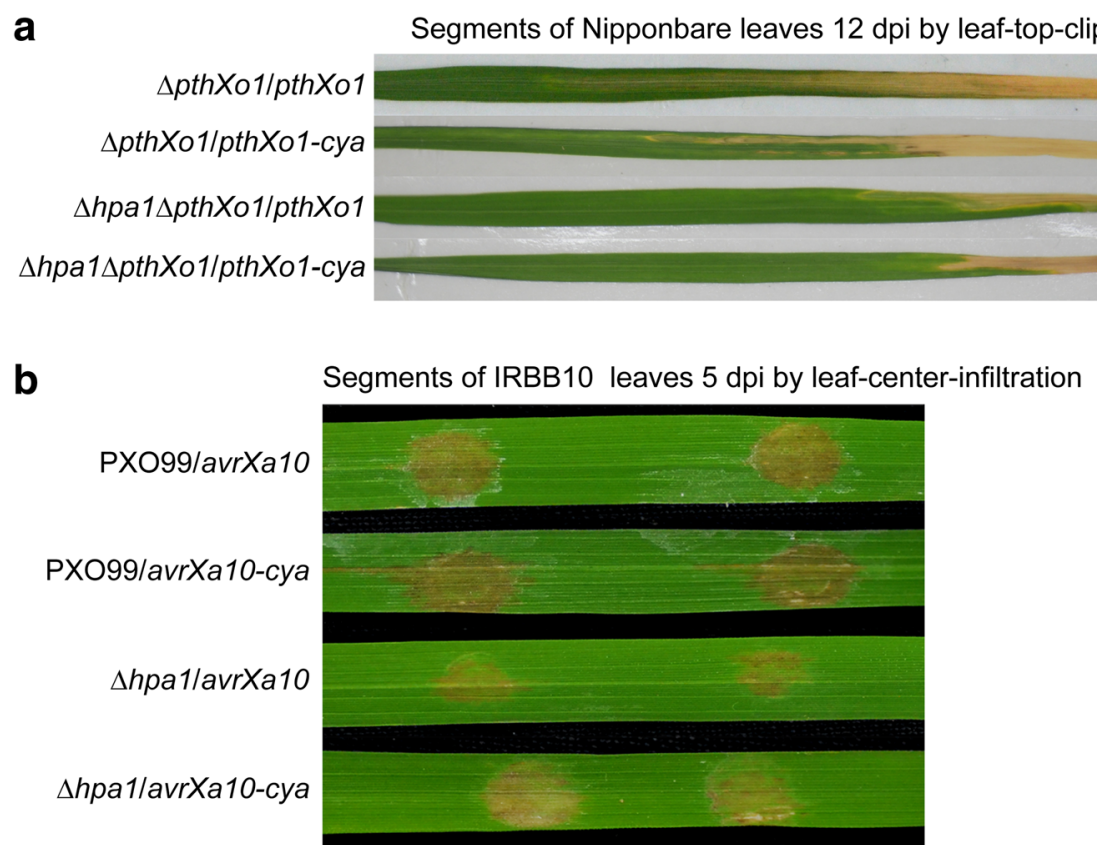

Fig. 3 The Cya tag does not affect the virulent role of PthXo1 (a) and the avirulent role of AvrXa10 (b). Leaves were photographed at $12 \mathrm{dpi}$ in (a) and 5 dpi in (b)

In the measurements of both PthXo1 (Fig. 5a) and AvrXa10 (Fig. 5b), little translocations were found with $\Delta h r c V$ itself, $\Delta h r c V / p t h X o 1-c y a$, or $\Delta h r c V / a v r X a 10-c y a$ due to the absence of HrcV-mediated secretion (Fig. 4). Furthermore, similar amounts of AvrXa10-Cya translocation were detected in IRBB10 leaves inoculation with recombinant bacterial strains PXO99/avrXa10-cya and $\Delta p t h X o 1 / a v r X a 10-c y a$, respectively (Fig. 5b). This indicates that the presence of PthXo1 does not influence the translocation of AvrXa10 from bacterial cells into the cytosol of IRBB10 cells.

In all experiments, bacterial populations in leaves had little effect on changes in TAL effector translocation within 12 hpi. At this time point, cAMP concentrations were measured to indirectly quantify translocated TAL effectors while in planta bacterial populations of different strains were almost similar regardless of hpa 1 deletion (Fig. 5b). Indeed, the biggest difference of the in planta populations between different strains was less than 3 times. In Nipponbare, $\Delta$ hpa1 $\Delta p t h X o 1 / p t h X o 1-c y a$ and $\Delta$ thXo1/pthXo1-cya showed logarithmic growth rates of 5.90 and $6.15 \mathrm{cfu} / \mathrm{leaf}$ (Fig. $5 \mathrm{~b}$ ), which were converted to a 1.7 -fold difference in actual bacterial populations. However, an 8.7-fold decrease in cAMP content was observed in Nipponbare leaves after inoculation with hpa1-deleted bacteria (Fig. 5a). In IRBB10, moreover, PXO99/avrXa10-cya and PXO994hpa1/avrXa10cya populations had similar growth rates, approximately logarithmic $5.7 \mathrm{cfu} /$ leaf (Fig. 5d), but leaf inoculation with hpa1-deleted bacterial cells resulted in a 6.3-fold reduction in cAMP content (Fig. 5b). Clearly, the quantitative changes in PthXo1 and AvrXa10 translocation were attributable to $h p a 1$ deletion, rather than differences in bacterial populations within leaf tissues, thereby indicating that Hpa1 indeed is a translocator of PthXo1 and AvrXa10.
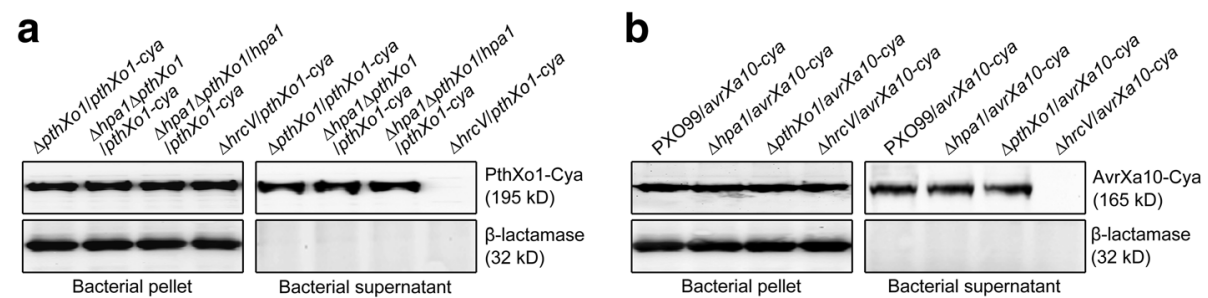

Fig. 4 Bacterial PthXo1 (a) and AvrXa10 (b) secretion assays. Two proteins had been fused to a cya sequence and were prepared as supernatants from bacterial cultures. Protein samples were analyzed by immunoblotting with the specific antibody against Cya and the specific antibody against the $\beta$-lactamase protein used as a lysis control 


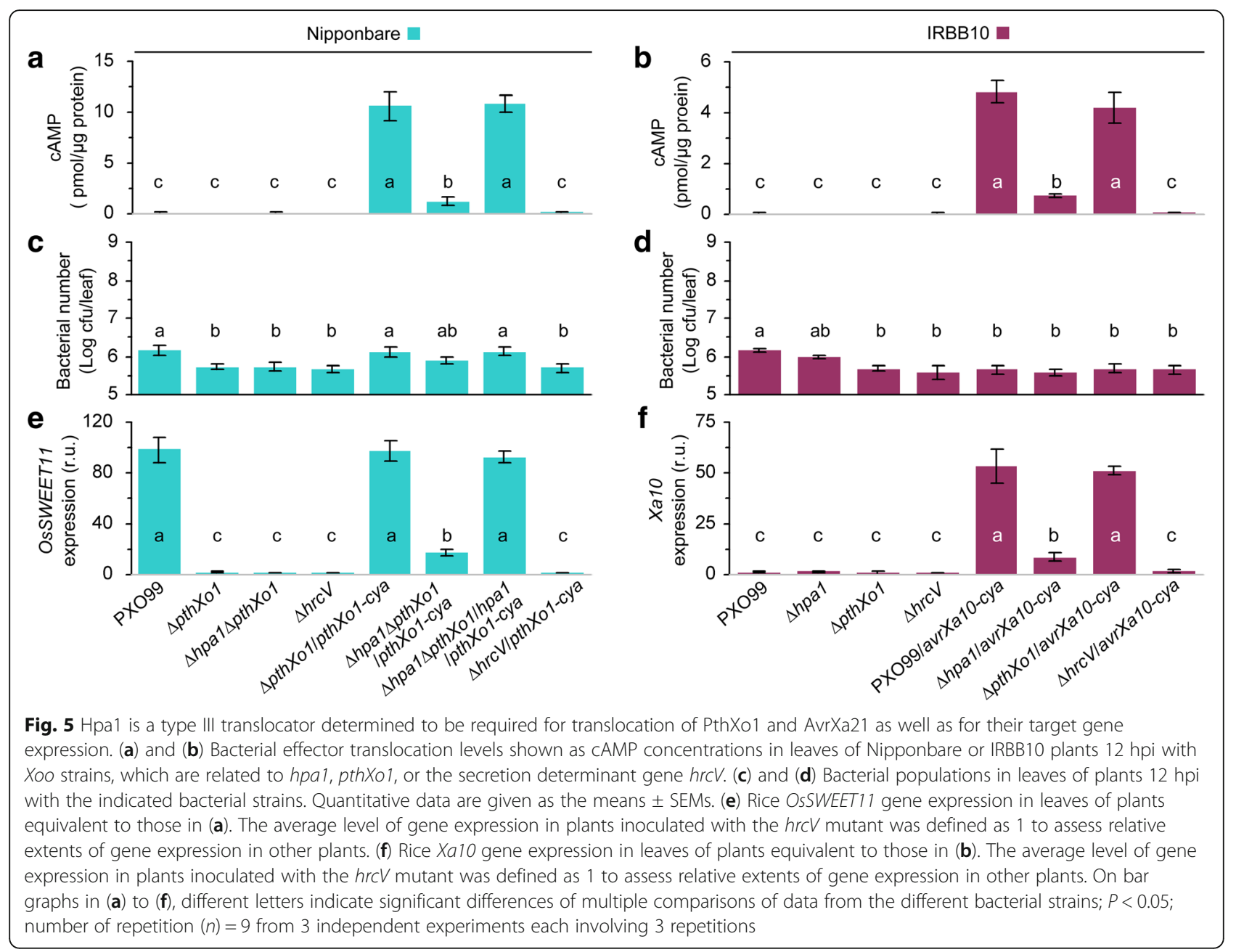

\section{Hpa1-mediated translocation of PthXo1 and AvrXa10 leads to expression of the effector target genes in rice cells}

To elucidate the subsequent effect of Hpa1-mediated translocation of PthXo1 on its virulent role executed via activating expression of the target gene SWEET11 [26], we determined SWEET11 transcript quantities in Nipponbare leaves following inoculation with proper Xoo strains (Fig. 5e). The analysis by RT-qPCR, namely real-time reverse transcriptase (RT) polymerase chain reaction (PCR), showed that SWEET11 was highly expressed in plants inoculated with the WT Xoo strain or recombinant strains containing functional pthXo1 and hpa1 genes. RT-qPCR data also indicated that SWEET11 expression was significantly $(P<0.01)$ decreased in Nipponbare leaves inoculated with bacteria in which hpal or pthXo1 or both was deleted.

RT-qPCR was also carried out to analyze the subsequent effect of Hpa1-mediated translocation of AvrXa10 on its function in activating expression of the target gene Xa10 [27] in leaves of IRBB10 seedlings inoculated with pertinent Xoo strains (Fig. 5f). Strong expression of Xa10 was induced by the recombinant Xoo strain that has an introduced avrXa10 gene, along with a functional hpal sequence. In comparison, Xa10 expression level incurred significant $(P<0.01)$ reductions when hpa1 or avrXa10 or both was absent in inoculated IRBB10 plants.

\section{The a-helical motif is required for the function of Hpa 1 as a T3SS translocator}

Given that the $\alpha$-helix motif present in the $\mathrm{N}$-terminal region of Hpal on its bioactivities [5, 14, 24, 25], we assumed that the motif is likely to serve as a determinant of the translocator function. This hypothesis was validated by fragment deletions toward the Hpal sequence (Fig. 6), followed by investigating the pathological performance of Hpa1 (Fig. 7). We generated Hpa1 mutant versions $\Delta \mathrm{N} 36, \Delta \mathrm{N} \alpha, \Delta \mathrm{C} \alpha$, and $\Delta \mathrm{NC} \alpha$ by deleting the first 36 residues, $\mathrm{N}$ - terminal $\alpha$-helix, $\mathrm{C}$-terminal $\alpha$-helix, and both $\alpha$-helices, respectively (Fig. 6). All mutant versions attenuated the virulent role of PthXo1 (Fig. 7) and 


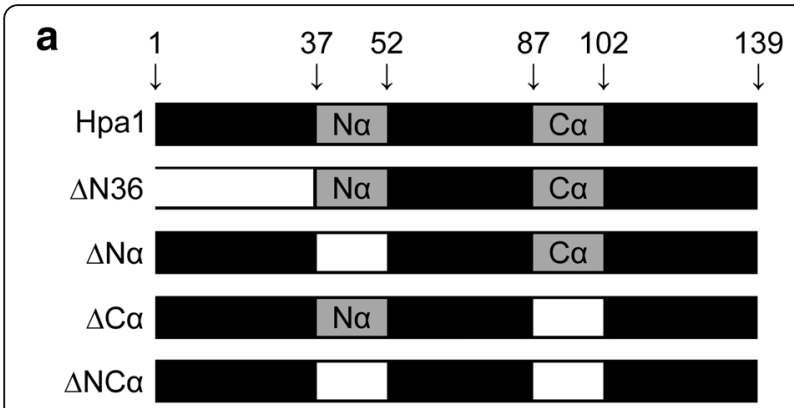

b

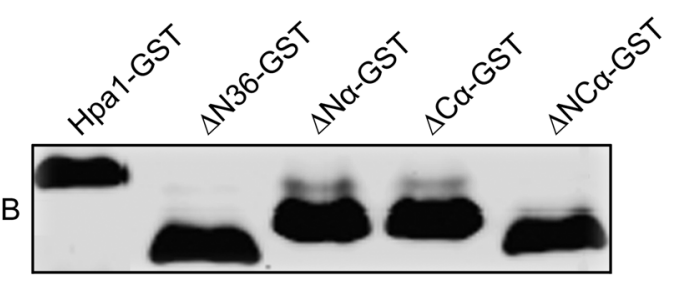

Fig. 6 Generation and immunoblotting of Hpa1 mutant versions compared with the canonical form. a Schematic diagrams showing full-length sequence and mutant versions of the Hpa1 protein. Mutants $\triangle N 36, \Delta N a, \Delta C a$, and aNC were generated by deleting the $\mathrm{N}$-terminal region made of 36 residues, the $\mathrm{N}$-terminal helix $(\mathrm{Na})$, the C-terminal helix (Ca), and both helices $(\mathrm{NCa})$, respectively. Amino acid sequence borders of these protein variants are pointed by arrowheads linked to the numbers of initial and terminal residue sites. $\mathbf{b}$ Immunoblotting. Each of Hpal variants was fused to a GST tag. Fusion proteins were produced by prokaryotic expression and analyzed by Western blotting hybridization with the GST antibody

impaired the avirulent function of AvrXa10 (Fig. 8). Virulence impairment by Hpa1 mutations caused evident reductions in both severities of bacterial blight (Fig. 7a, b) and levels of OsSWEET11 expression (Fig. 7c) in Nipponbare. In Cya reporting assays (Fig. 7c) with similar populations of different bacterial strains (Fig. 7e), PthXo1 translocation was severely compromised by Hpa1 mutations compared to that observed with the canonical protein (Fig. 7d).

\section{Discussion}

We have identified Hpal as a translocator of TAL effectors, PthXo1 and AvrXa10 of Xoo, based on the quantitative changes in translocation and function of both TAL effectors with and without Hpa1. The performance of Hpa1 in all parallel experiments were in agreement with the functional characteristics of type III translocators. In essence, the translocators regulate the translocation of certain effectors, rather than the secretion by T3SS, and regulate virulent or avirulent roles of effectors depending on plant responses $[8,9,22]$. Therefore, we conclude that Hpa1 functions as a type III hydrophilic translocator that regulates the virulent role of PthXo1 and the avirulent role of AvrXa10 in susceptible and resistant rice varieties, respectively.
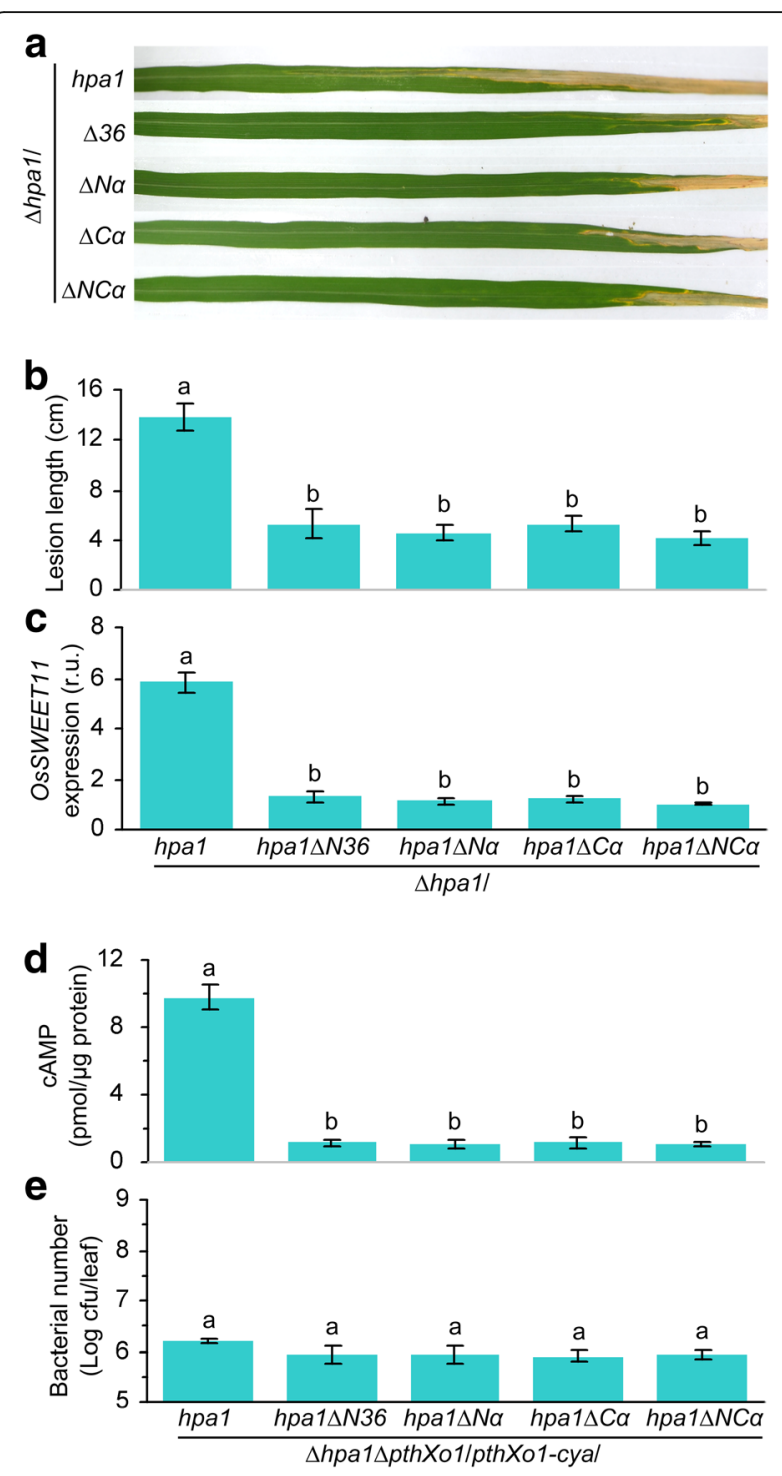

Fig. $7 \mathrm{Hpa1}$ a-helices play a critical role in PthXo1 translocation. a-e, Bacterial hpa1 mutants $\triangle N 36, \Delta N a, \Delta C a$, and aNC were generated by deleting hpal sequence regions, which encode the $\mathrm{N}$-terminal region made of 36 residues, the $\mathrm{N}$-terminal a-helix, the C-terminal a-helix, and both a-helices, respectively. Resulting mutant genes were introduced into the $\Delta$ hpal or $\Delta$ pal $\Delta p$ thXo1/pthXo1-cya mutant of Xoo strain PXO99. Recombinant bacteria were used in Nipponbare inoculation by the leaf-top-clipping method. Inoculated plants were subjected to the following analyses. (a) Bacterial blight symptoms on leaves photographed at day 12 after inoculations. b Blight lesion length on leaves from (a). c Relative units (r.u.) of OsSWEET11 gene expression in leaves at $12 \mathrm{hpi}$. The average expression level of OSSWEET 11 in the plant with $\Delta$ hpal/hpa1 $\Delta N C$ a-helix was defined as 1 to evaluate relative extents of gene expression in plants inoculated with other XoO strains. (d) The content of CAMP from PthXo1-Cya activity in cytoplasm of leaf cells at $12 \mathrm{hpSi}$. In (b) to (e), data are the means \pm SEMs; different letters on bar graphs indicate significant differences in multiple comparisons for the bacterial strains; $P<0.05 ; n=9$ repetitions from 3 independent experiments each involving 3 repetitions 


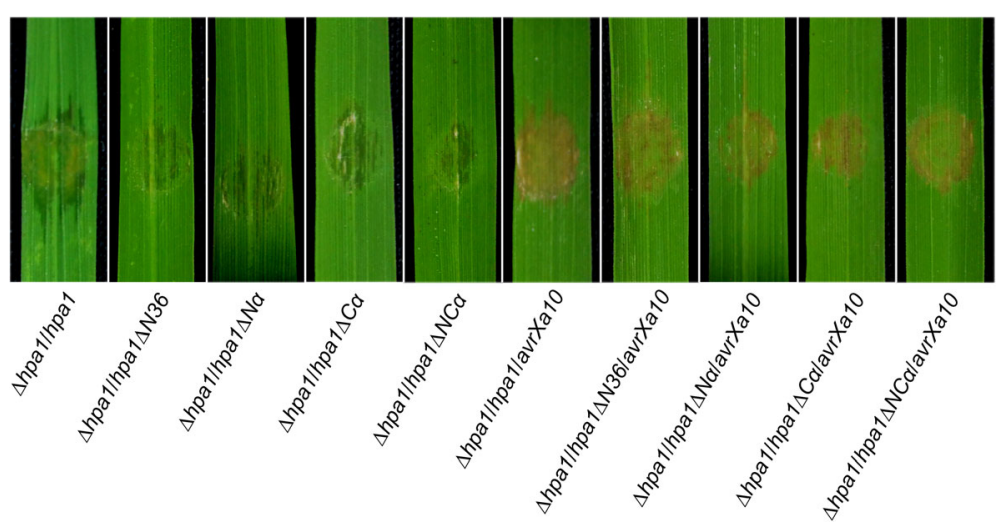

Fig. 8 Deletions of hpal sequence regions affect TAL effector functions. TAL effector functions refer to the virulent role of PthXo1 and the avirulent role of ArvXa10 on IRBB10. Fourteen-day-old IRBB10 seedlings were inoculated by leaf infiltration with every bacterial suspension of the indicated strains; leaves were photographed at 5 dpi

The translocator Hpa1 may not be specifically required for the translocation of selected T3SS substrates but also contributes to the translocation of all effectors of a given bacterial strain. This hypothesis remains to be validated in the future by studying more effectors, at least including Xops. Indeed, characterization of the molecular mechanism that governs effector translocation is merely in the initial stage while numerous studies are needed to elucidate translocation of different effectors from plant-pathogenic bacteria. For example, an Xoo strain produces near 30 Xops [18] but none of them have been studied with respect to translocation. Moreover, the composition of type III translocon and the number of translocators present in a species or a strain of plant-pathogenic bacteria are still not known although the issues have been well demonstrated in animal-pathogenic bacteria [5]. While many works are needed to identify the translocator repertoire and translocon composition, the characterization of Hpal as a TAL effector translocator is a definite step forward to better understanding of the composition of type III translocon in plant-pathogenic bacteria.

In addition to Hpa1, HrpF is also required for TAL effector translocation [22, 28]. HrpF is the first type III translocator discovered in plant-pathogenic bacteria and has been described as a translocator of AvrBs3 in $X$. campestris pv. vesicatoria [22], the bacterial spot pathogen of pepper [38]. HrpF is highly conserved in the Xanthomonas genus [36] and contains two predicted TM domains [22, 39], which are characteristic of type III hydrophobic translocators $[2,5]$. The C-terminal region of $\mathrm{HrpF}$ is essential for AvrBs3 translocation, whereas the $\mathrm{N}$-terminus contains a secretion signal. Thus, secretion and translocation are sequential but independent processes, in agreement with $\mathrm{HcrV}$-dependent secretion and Hpa1-mediated translocation of Xoo PthXo1 and AvrXa10 (Fig. 2).
Additional translocators may cooperate with Hpa1 and HrpF to mediate TAL effector translocation. Sugio and colleagues (2005) found that AvrXa10-containing hrpF hpa1 double mutant was impaired in virulence and avirulence to susceptible and resistant rice varieties IR24 and IRBB10, respectively. As the authors stated that the double mutant elicited the HR in IRBB10 and noted "data not shown", we guess that the HR extent was probably weakened in line with the avirulence reduction by $\mathrm{HrpF}$ and Hpal knockout. As the extent of virulence or avirulence depends on the quantity of effector translocation, the performance of $h r p F$ hpal double mutant [36] is consistent with the effects of Hpal on PthXo1 and AvrXa10 translocation observed in our study. Sugio and colleagues (2005) hypothesized that effector translocation may involve additional translocators, plant cell endocytosis, direct secretion after pilus penetration of plant cells, or unknown effects of HrpF on effector activities. Animal-pathogenic bacteria possess one hydrophilic and two hydrophobic translocators, which are concomitantly required for effector translocation and are assumed to be assembled chronologically into a translocon $[2,5]$. This model agrees not only with the performance of $h r p F$ hpa1 double mutant [36] but also with the critical role of Hpa1 in TAL effector translocation. Further evidence is challenging yet fairly worthy to elucidate whether effector translocation is subject to multiple regulations, including plant cell endocytosis, effector import into plant cells after pilus penetration of plant PMs, and the effect of HrpF or the other translocators on effector activities.

It was reported that Xoo HrpF needed Hpa2 to coregulate AvrXa10 translocation [28]. Hpa2 is a type III accessary protein and a lytic transglycosylase that decomposes bacterial cell walls [40]. In the canonical secretion of type III accessary proteins, lytic transglycosylases potentially associate with the bacterial periplasm and degrade the peptidoglycan substrate $[41,42]$. This activity presumably 
enlarges the periplasmic mesh pores to accommodate the T3SS machinery, which then extend to the interface between bacterial and eukaryotic cells [43-45]. Subsequently, a hydrophilic translocator is secreted to initiate translocon assembly [2, 3, 6-9]. Therefore, Hpa1 may be critical for translocon formation as a prerequisite for TAL effector translocation [5].

The protein mutation analysis suggests that the pair of $\alpha$-helix motif is important for the function of Hpal as a type III translocator. However, the present data can not exclude other parts of the Hpal sequence. All the truncated Hpa1 proteins tested in this study, including the version lacking the $\mathrm{N}$-terminal 36 amino acid residues, showed loss of virulence/avirulence functions like the hpa1 null mutant. Therefore, it is necessary to study in the future whether the biological function of Hpal involves other parts of the protein sequence.

\section{Conclusions}

Meticulous genetic analyses indicate that Hpa1 contributes to a substantial part of the virulent role that PthXo1 plays in the susceptible rice variety. Genetic data also supports a marked effect of Hpal on the avirulent role of AvrXa10 in the resistant rice variety. Immunoblotting analysis demonstrates the critical function of Hpal in mediating the effector translocation from bacterial cells into cytosol of rice cells. This function of Hpal as a type III translocator has subsequent effects on the TAL effector target genes in terms of expression levels. This establishes the mechanistic linkage between Hpa1 recognition by rice plasma membrane and pathological role of the effectors that experience translocation under regulation by the translocator. We do not know how Hpal cooperates with HrpF in the hypothetic translocon assembly, and this will the subject of further studies.

\section{Additional file}

Additional file 1: Table S1. Strains and plasmids used and created in this study. Table S2. Information on genes tested and primers used in this study. (DOCX $35 \mathrm{~kb}$ )

\section{Abbreviations}

Cya: calmodulin-dependent adenylate cyclase; HR: hypersensitive response; PM: plasma membrane; T3SS: type III secretion system; TAL: transcription activator-like; Xoo: Xanthomonas oryzae pv. oryzae, pathogen of rice bacterial blight; Xop: Xanthomonas outer proteins

\section{Acknowledgements}

This study was supported by NSFC (grant number 31772247), China National Special Public Welfare Industry Program (2017YFD0200901) and the Jiangsu Provincial Scientific Plan Program (BK20150668).

\section{Funding}

Natural Science Foundation of China (NSFC) grant number 31772247; China National Special Public Welfare Industry Program, grant number 2017YFD0200901; Jiangsu Provincial Scientific Plan Program grant number
BK20150668. The funding bodies had no role in the design of the study and collection, analysis, and interpretation of data and in writing the manuscript.

\section{Availability of data and materials}

All data generated or analysed during this study are included in this published article and its supplementary information files.

\section{Authors' contributions}

The work presented here was carried out as a collaboration among all authors. XW performed the protein secretion and translocation analyses, quantified the gene expression, and drafted the manuscript. LZ measured the in planta bacterial populations and drafted and revised the manuscript. $\mathrm{HJ}$ constructed the bacterial mutants, carried out the virulence assay, and drafted the manuscript. XM performed the immunoblotting experiment. PL and JW retrieved the data from the databases and analyzed the data obtained in this study. HD designed the study and revised the paper. All authors read and approved the final manuscript.

Ethics approval and consent to participate Not applicable.

\section{Consent for publication}

Not applicable.

\section{Competing interests}

The authors have declared that no competing interests exist.

\section{Publisher's Note}

Springer Nature remains neutral with regard to jurisdictional claims in published maps and institutional affiliations.

\section{Author details}

${ }^{1}$ Department of Plant Pathology, College of Plant Protection, Nanjing Agricultural University, Nanjing 210095, Jiangsu Province, China. ${ }^{2}$ Present address: Department of Biology, College of Life Sciences, Jiangsu Formal University, Xuzhou 221116, Jiangsu Province, China.

Received: 5 October 2017 Accepted: 27 August 2018

Published online: 04 September 2018

\section{References}

1. Alfano JR, Collmer A. Type III secretion system effector proteins: double agents in bacterial disease and plant defense. Annu Rev Phytopathol. 2004; 42:385-414

2. Büttner D. Protein export according to schedule: architecture, assembly, and regulation of type III secretion systems from plant- and animal-pathogenic bacteria. Microbiol Mol Biol Rev. 2012;76:262-310.

3. Chatterjee S, Chaudhury S, McShan AC, Kaur K, De Guzman RN. Structure and biophysics of type III secretion in bacteria. Biochemistry. 2013;52:2508-17.

4. Bogdanove AJ, Voytas DF. TAL effectors: customizable proteins for DNA targeting. Science. 2011;333:1843-6.

5. Ji H, Dong H. Key steps in type III secretion system (T3SS) towards translocon assembly with potential sensor at plant plasma membrane. Mol Plant Pathol. 2015a;16:762-73.

6. Espina M, Ausar SF, Middaugh CR, Picking WD, Picking WL. Spectroscopic and calorimetric analyses of invasion plasmid antigen D (IpaD) from Shigella flexneri reveal the presence of two structural domains. Biochemistry. 2006; 45:9219-27.

7. Mueller CA, Broz P, Cornelis GR. The type III secretion system tip complex and translocon. Mol Microbiol. 2008;68:1085-95.

8. Kvitko BH, Ramos AR, Morello JE, Oh HS, Collmer A. Identification of harpins in Pseudomonas syringae pv. tomato DC3000, which are functionally similar to HrpK1 in promoting translocation of type III secretion system effectors. J Bacteriol. 2007;189:8059-72.

9. Bocsanczy AM, Nissinen RM, Oh CS, Beer SV. HrpN of Erwinia amylovora functions in the translocation of DspA/E into plant cells. Mol Plant Pathol. 2008;9:425-34.

10. Charkowski AO, Alfano JR, Preston G, Yuan J, He SY, Collmer A. The Pseudomonas syringae $\mathrm{pv}$. tomato $\mathrm{HrpW}$ protein has domains similar to harpins and pectate lyases and can elicit the plant hypersensitive response 
and bind to pectate. J Bacteriol. 1998;180:5211-7. http://jb.asm.org/content/ 180/19/5211.long

11. Kim JF, Beer SV. HrpW of Erwinia amylovora, a new harpin that contains a domain homologous to pectate lyases of a distinct class. J Bacteriol. 1998; 180:5203-10. http://jb.asm.org/content/180/19/5203.long

12. Choi MS, Kim W, Lee C, Oh CS. Harpins, multifunctional proteins secreted by gram-negative plant-pathogenic bacteria. Mol Plant-Microbe Interact. 2013; 26:1115-22.

13. Oh CS, Beer SV. AtHIPM, an ortholog of the apple HrpN-interacting protein, is a negative regulator of plant growth and mediates the growthenhancing effect of HrpN in Arabidopsis. Plant Physiol. 2007;145:426-36.

14. Li L, Wang H, Gago J, Cui H, Qian Z, Kodama N, Ji H, Tian S, Shen D, Chen Y, et al. Harpin Hpa1 interacts with aquaporin PIP1;4 to promote the substrate transport and photosynthesis in Arabidopsis. Sci Rep. 2015;5:17207.

15. Haapalainen M, Engelhardt S, Küfner I, Li CM, Nürnberger T, Lee J, Romantschuk M, Taira S. Functional mapping of harpin HrpZ of Pseudomonas syringae reveals the sites responsible for protein oligomerization, lipid interactions and plant defence induction. Mol Plant Pathol. 2011;12:151-66.

16. Sang S, Li X, Gao R, You Z, Lü B, Liu P, Ma Q, Dong H. Apoplastic and cytoplasmic location of harpin protein $\mathrm{Hpal}_{\text {xoo }}$ plays different roles in $\mathrm{H}_{2} \mathrm{O}_{2}$ generation and pathogen resistance in Arabidopsis. Plant Mol Biol. 2012;79:375-91.

17. Zhu WG, MaGbanua MM, White FF. Identification of two novel hrpassociated genes in the hrp gene cluster of Xanthomonas oryzae pv. oryzae. J Bacteriol. 2000;182:1844-53.

18. White FF, Potnis N, Jones JB, Koebnik R. The type III effectors of Xanthomonas. Mol Plant Pathol. 2009;10:749-66.

19. Bonas U, Stall RE, Stskawicz BJ. Genetic and structural characterization of the avirulence gene avrBs3 from Xanthomonas campestris pv campestris. Mol Gen Genet. 1989;218:127-36.

20. Boch J, Bonas U. Xanthomonas AvrBs3 family-type III effectors: discovery and function. Annu Rev Phytopathol. 2010;48:419-36.

21. Roden JA, Belt B, Ross JB, Tachibana T, Vargas J, Mudgett MB. A genetic screen to isolate type III effectors translocated into pepper cells during Xanthomonas infection. Proc Natl Acad Sci U S A. 2004;101:16624-9.

22. Büttner $D$, Nennstiel $D$, Klüsener B, Bonas U. Functional analysis of HrpF, a putative type III translocon protein from Xanthomonas campestris pv. vesicatoria. J Bacteriol. 2002:184:2389-98.

23. Ji ZL, Song CF, Lu XZ, Wang JS. Two coiled-coil regions of Xanthomonas oryzae pv. oryzae harpin differ in oligomerization and hypersensitive response induction. Amino Acids. 2011;40:381-92.

24. Wang XY, Song CF, Miao WG, Ji ZL, Wang X, Zhang Y, Zhang JH, Hu JS, Borth W, Wang JS. Mutations in the N-terminal coding region of the harpin protein Hpa1 from Xanthomonas oryzae cause loss of hypersensitive reaction induction in tobacco. Appl Microbiol Biotechnol. 2008;81:359-69.

25. Li XJ, Zhao YY, You ZZ, Dong HS, Zhang CL. Harpin Hpa1 needs nitroxyl terminus to promote vegetative growth and leaf photosynthesis in Arabidopsis. J Biosci. 2014;39:127-37.

26. Yang B, Sugio A, White FF. Os8N3 is a host disease-susceptibility gene for bacterial blight of rice. Proc Natl Acad Sci U S A. 2006;103:10503-8.

27. Tian D, Wang J, Zeng X, Gu K, Qiu C, Yang X, Zhou Z, Goh M, Luo Y, Murata-Hori $M$, et al. The rice TAL effector-dependent resistance protein XA10 triggers cell death and calcium depletion in the endoplasmic reticulum. Plant Cell. 2014;26:497-515.

28. Li YR, Che YZ, Zou HS, Cui YP, Guo W, Zou LF, Biddle EM, Yang CH, Chen GY. Hpa2 required by HrpF to translocate Xanthomonas oryzae transcriptional activator-like effectors into rice for pathogenicity. Appl Environ Microbiol. 2011;77:3809-18.

29. Makino S, Sugio A, White F, Bogdanove AJ. Inhibition of resistance genemediated defense in rice by Xanthomonas oryzae pv. oryzicola. Mol PlantMicrobe Interact. 2006;19:240-9.

30. Tsuge S, Furutani A, Fukunaka R, Oku T, Tsuno K, Ochiai H, Inoue Y, Kaku H, Kubo Y. Expression of Xanthomonas oryzae pv. oryzae hrp genes in XOM2, a novel synthetic medium. J Gen Plant Pathol. 2002;68:363-71.

31. Shi LW. SPSS19.0 statistical analysis from accidence to conversance (in Chinese). Beijing: Tsinghua University Press; 2012. p. 109-43.

32. Ge J, Li B, Shen D, Xie J, Long J, Dong H. Tobacco TTG2 regulates vegetative growth and seed production via the predominant role of ARF8 in cooperation with ARF17 and ARF19. BMC Plant Biol. 2016;16:126.

33. Eisenhart $\mathrm{C}$. The assumptions underlying the analysis of variance. Biometrics. $1947 ; 3(1): 1-21$
34. Tian S, Wang X, Li P, Wang H, Ji H, Xie J, Qiu Q, Shen D, Dong H. Plant aquaporin AtPIP1;4 links apoplastic $\mathrm{H}_{2} \mathrm{O}_{2}$ induction to disease immunity pathways. Plant Physiol. 2016;171:1635-50.

35. Zhai Y, Ping Li P, Mei Y, Xiaochen Chen X, Xu H, Zhou X, Dong H, Zhang C, Jiang $W$. Three MYB genes coregulate the phloem-based defence against English grain aphid in wheat. J Exp Bot. 2017;68 https://doi.org/10.1093/jxb/erx204.

36. Sugio A, Yang B, White FF. Characterization of the hrpF pathogenicity peninsula of Xanthomonas oryzae pv. oryzae. Mol Plant-Microbe Interact. 2005;18:546-54.

37. Hartmann N, Büttner D. The inner membrane protein HrcV from Xanthomonas spp. is involved in substrate docking during type III secretion. Mol Plant-Microbe Interact. 2013;26:1176-89.

38. Noël L, Thieme F, Nennstiel D, Bonas U. Two novel type III-secreted proteins of Xanthomonas campestris pv. vesicatoria are encoded within the Hrp pathogenicity island. J Bacteriol. 2002;184:1340-8.

39. Huguet $\mathrm{E}$, Bonas U. HrpF of Xanthomonas campestris pv. vesicatoria encodes an $87-k D a$ protein with homology to NoIX of Rhizobium fredii. Mol PlantMicrobe Interact. 1997;10:488-98.

40. Zhang JH, Wang $X Y$, Zhang $Y$, Zhang GY, Wang JS. A conserved Hpa2 protein has lytic activity against the bacterial cell wall in phytopathogenic Xanthomonas oryzae. Appl Microbiol Biotechnol. 2008;79:605-16.

41. Mushegian AR, Fullner KJ, Koonin EV, Nester EW. A family of lysozyme-like virulence factors in bacterial pathogens of plants and animals. Proc Natl Acad Sci U S A. 1996:93:7321-6.

42. Ward DV, Draper O, Zupan JR, Zambryski PC. Peptide linkage mapping of the Agrobacterium tumefaciens vir-encoded type IV secretion system reveals protein subassemblies. Proc Natl Acad Sci U S A. 2002;99:11493-500.

43. Koraimann G. Lytic transglycosylases in macromolecular transport systems of gram-negative bacteria. Cell Mol Life Sci. 2003;60:2371-88.

44. Zahrl D, Wagner M, Bischof K, Bayer M, Zavecz B, Beranek A, Ruckenstuhl C, Zarfel GE, Koraimann G. Peptidoglycan degradation by specialized lytic transglycosylases associated with type III and type IV secretion systems. Microbiology. 2005;151:3455-67.

45. Oh HS, Kvitko BH, Morello JE, Collmer A. Pseudomonas syringae lytic transglycosylases coregulated with the type III secretion system contribute to the translocation of effector proteins into plant cells. J Bacteriol. 2007; 189:8277-89.

Ready to submit your research? Choose BMC and benefit from:

- fast, convenient online submission

- thorough peer review by experienced researchers in your field

- rapid publication on acceptance

- support for research data, including large and complex data types

- gold Open Access which fosters wider collaboration and increased citations

- maximum visibility for your research: over $100 \mathrm{M}$ website views per year

At $\mathrm{BMC}$, research is always in progress.

Learn more biomedcentral.com/submissions 